\title{
Penumbra: Doctoral support as drama: From the 'lightside' to the 'darkside'. From front of house to trapdoors and recesses
}

Prof Gina Wisker,

University of Brighton, UK;

University of Johannesburg, South Africa.

Dr Gillian Robinson,

Anglia Ruskin University, UK;

Asst. Prof Søren S. E. Bengtsen,

Aarhus University, Denmark.

\begin{abstract}
Much international doctoral learning research focuses on the personal, institutional and learning support provided by supervisors through supervisory dialogues, managed relationships, and the 'nudging' of robust, conceptual, critical and creative work. Other work focuses on the stresses experienced in both supervisor-student relationships and the doctoral journey itself. Some considers formal and informal learning communities supporting students on their research journeys, and roles played by families, friends and others, sometimes offering encouragement and sometimes an added stress.

However, little has yet been explored, exposed and shared concerning the often unofficial, largely unrecognised range of meaningful others in students' 'life-worlds', variously supporting their doctoral learning journeys in terms of research, writing and editing. Research, based in experience and interviews with doctoral students and supervisors from UK and international contexts, reveals a wide range of support (termed 'the penumbra'), both university sanctioned ('lightside'), as well as less well recognised often unsanctioned support ('darkside') on the doctoral research and writing learning journey, opening up questions about doctoral student needs, and the range of support provided, both legitimately and well known, and perhaps less legitimately and less well known. This work concentrates in the main on the 'darkside'.
\end{abstract}

\section{Introduction}

Much literature on doctoral student experiences during their learning journeys can be seen in relation to three dimensions: learning, personal and institutional. It focuses on encouraging development of research skills, and success on the research journey, including crossing of conceptual thresholds resulting in critical, conceptual and creative work, and contribution to knowledge (Kiley \& Wisker, 2009; Wisker \& Robinson, 2009). Personal, learning and institutional support is largely provided by formally established supervisor-student relationships (Wisker, 2012), through supervisory dialogues, managed relationships, and the 'nudging' of robust, conceptual, critical and creative work. It is augmented by required, additional courses, to develop research methods, writing and teaching skills

Research reported here is based on our own experience in UK and international doctoral supervision and management of doctoral programmes, literature, and new UK and internationally 
based interviews with doctoral students and graduates, 2015-6. From such sources, we begin to identify those variously playing parts in doctoral student research and writing support as resembling a 'penumbra', a light around the main activity, moving as light can round a person or object, from the 'lightside' (overt, positive, acknowledged) to the 'darkside' (no inadvertent cultural identification intended-. Defined here only as covert, often unacknowledged). The dictionary definition of 'penumbra' is 'a peripheral or indeterminate area or group', implying diversity and complexity. This imagery resonates with Marginson et al (in Pearson, Evans, \& Macaulay, 2016), who speak of the diversity and complexity of 'experienced environments' for doctoral candidates.

Considering support being played out in the spotlight, as overt, acknowledged as legitimate, and some more covert, we decided to further our analogy to identify lead players in this broad process and so adopt an analogy of dramatic production roles to explore work of the cast and production team supporting PhD students' work, and using metaphors of light, the penumbra, and dramatic production. Later work could further explore the experience dramatically in ethnodramatic terms (Fitzpatrick, Mullen, \& O'Connor, 2015).

\section{The higher education sprawl}

The domain of support and development lying beyond the institutionally provided and sanctioned consists of parts of doctoral students' 'life-worlds' traditionally lying 'outside' the formal educational focus of universities, including students' private lives, for example, their relationships to family, friends and colleagues outside academia. As Hopwood, Harris-Huemmert, McAlpine and Wagstaff underline, we often forget that doctoral students are also 'parents, siblings, daughters/sons, and friends; they have other interests to pursue, health and finance to maintain, and domestic lives to run' (Hopwood et al, 2011, p. 218). Along with supervisor support, family and friend support emotional, financial and as critical friends might most often be considered overt, legitimate, 'lightside'.

This could suggest that the traditionally given primacy to doctoral supervision and supervisors as the keystone to good learning experiences during the PhD programme might underestimate the effects of others who also have a direct or indirect effect upon the research including relatives, friends, and critical friends in the broader doctoral learning community who support the research and writing in a positive way, offering critical friendship for psychological, reading, writing and proofing support, all of which can be celebrated upon completion. Lave and Wenger (1992) discuss legitimate peripheral participation which engages the student with others. Similarly McAlpine \& McKinnon (2013) found that 'on a day-to-day basis, students depended as frequently on peers, friends, and family as they did on their supervisors, drawing on each relationship for different kinds of support' (McAlpine \& McKinnon, 2013, p. 265), concluding 'supervisors, while important, are not paramount in the doctoral journey' (McAlpine \& McKinnon, 2013, p. 278). Vekkaila, Pyhältö, and Lonka (2013) consider student disengagement while Morris and Wisker (2011) explore strategies for resilience, including supportive others. We suggest that these supportive others resemble a production team or a dramatic cast, with the supervisor as producer (efficient or otherwise).

In another empirical study, Jazvac-Martek, Chen and McAlpine (2011) disclose the many diverse interactions, tasks and odd-jobs that are part of doctoral students' academic life, and their extended life-worlds, identifying 'a plenitude of supportive and critical interactions occurring beyond the primary relationship with the supervisor' (Jazvac-Martek, Chen, \& McAlpine, 2011, p. 25). Turunen's (2012) doctoral narrative indicates that such activities could include 'snack studies' (Turunen, 2012, p. 72) - research done outside the doctoral student's own PhD project. Even though such activities are generally discouraged by supervisors, they might prove 'nourishing' (ibid.) opening 
unexpected career opportunities (Turunen, 2012). Elliot and her research team (2015) mapped a variety of extra-curricular activities helping students become further institutionally acculturated, termed 'third spaces', including 'volunteering in [a] (...) bookshop, going to sports clubs, joining a church choir, or looking after young children'. For one international student in the study, 'going to the pub opened doors to deeper cultural understanding and social relations with local people' (Elliot, Reid, \& Baumfield, 2015, p. 10). This myriad of intertwined educational and 'life-world' domains previously acknowledged and termed 'nested contexts' (McAlpine and Norton, 2006) and more recently, '[t]he sprawling spaces of doctoral supervision' (Bengtsen, 2016a), where "'sprawl" an alternative guiding metaphor for doctoral supervision, 'does not denote an uncontrollable chaotic force' rather a 'non-linear, plastic understanding of learning spaces, not limited to formal and informal settings', including 'non-formal spaces' (Bengtsen, 2016a, p. 61).

\section{Darkness and desire in doctoral higher education}

Sometimes, however, supervisor behaviours and power relations are less than supportive of students and their endeavours. Manathunga and Grant both emphasise the darker side of supervision, the 'master/slave' relationship of unbalanced power and silencing (Manathunga, 2007; Grant 2008). This could be differentially problematic, more unbalanced when gender and ethnicity play into the relationship. As Carter and Laurs (2014) highlight, "[w]omen with an abuse history can find that supervisory "rigour" stunningly disempowers them. Such women may also find it hard to claim an authoritative voice as an expert in the field when historically they have relied on keeping a low profile to avoid trouble' (Carter \& Laurs, 2014, p. 37). Grant warns us to not assume too much rationality in the actions of doctoral students (and their supervisors), suggesting we take a more focused study of passions and desires playing out and shaping doctoral journeys. As Grant notes, to fully understand the 'life-world' of doctoral students, we need to include in our perspective on supervision and doctoral pedagogy 'these complex and contradictory desires' and how they are 'mobilized in the supervision interaction; they do not remain safely contained in the mind but animate the body' (Grant, 2001, p. 16). These can generate doubt, insecurity and vulnerability during the doctoral journey which Manathunga suggests may lead to feelings of disorientation, explained by homeliness (actually unhomeliness), since '[t]he trope of homeliness seeks to capture the cultural alienation, sense of uncertainty and discomfort that people experience as they adjust to new cultural practices' (Manathunga, 2014, p. 136).

Extra-curricular spaces and domains are not necessarily the physical university but blind angles and dark corners of the formalised curriculum and institutional framework (Wisker \& Robinson 2012), considering students who fall off the radar, becoming 'lost' in the university graduate/doctoral college system, seen, for example, when they shift from one supervisor to another, or are moved between research programmes or departmental units. At such times students risk becoming 'doctoral "orphans"' (Wisker \& Robinson, 2012, p. 140). Although this study found that doctoral orphans who survive and gain their PhDs developed ownership and resilience to do so, sound characteristics in academics and researchers, only the graduates, necessarily the resilient successful ones, were available for that research. We might well ask what happened to those who entirely fell off the radar and out of the programme, and what legitimate university, family and friend support should or could have been available to them. Students report losing their way in the sometimes labyrinthine complexity of big graduate school systems, conceptualised as 'institutional darkness' within higher education (Bengtsen \& Barnett, 2016; Bengtsen, 2016b; Elliot, Baumfield, Reid, \& Makara, 2016). Forms of 'doctoral darkness' focus on the 'sides of [doctoral] education, which may be dim, obscure or caught in a blind angle' (Bengtsen \& Barnett, 2016, p. 2). We argue that

we need more elaborate language and subtle concepts for grasping [doctoral] students' 
experience of failure and let down, when struggling with and withdrawing from difficult courses never completed; for half-formed ideas and crippled thoughts, full of passion and heart, but unfit for the academic genre of writing; and for interior imaginative wanderings that seldom see the light of day (ibid.).

We know these things happen and play a major part in doctoral experience, but still have little knowledge about how they play more specifically into completion, quality of research, the PhD thesis, and further career opportunities.

What we also know relatively little about, and the main focus in the following sections of the paper, is the work of the full range of the 'cast' or 'production team': the extent and kind of parts played by known, 'lightside', and legitimated 'supporting actors' such as university provided and/or sanctioned support, family, friends, and professional others including the programme administrator, transcriber, translator and proof-reader. Importantly, we know even less about support provided by unknown, unacknowledged others; those hidden 'darkside' 'actors', offering perhaps more covert, unacknowledged support in the students' doctoral research, writing and learning drama.

Our ongoing research on the 'penumbra' of such support, both 'lightside' (legitimated) and 'darkside' (less acknowledged, sometime illegitimate) springs from experience and observation, interviews with doctoral students and graduates, and dialogue with research concerning doctoral student support. Work reported here focuses mainly on the lesser known 'darkside'.

\section{Methodology and methods}

\section{Data collection}

This research springs initially from and consciously reflects our experiences of supervision, and for two of us, 'guardian supervisor' support for and earlier research with a large cohort-based PhD programme of international, mid-career doctoral students (1998-201)4. It also springs from workshops with supervisors and postgraduates 1998-2017 and familiarity with the systems and practices of supervision in the UK, South Africa, other African countries, Australasia, Israel, Saudi Arabia, the Republic of Ireland, Canada, Norway, Sweden and Denmark, locations from which we also sought respondents for research reported here. We decided to explore the experiences of doctoral students and supervisors of working with 'others' in the penumbra of support along the doctoral journey, after we became aware of the plentiful supportive cast. Some responses from our earlier work feed into this discussion as background where appropriate.

Narrative interviewing was conducted during 2015-2016, using semi-structured open-ended interviews inspired by the phenomenological research interview tradition (McCracken, 1988; Holstein \& Gubrium, 1995; Brinkmann \& Kvale, 2014). Postgraduate and graduated respondents were recruited by enquiring if they (or their students) had worked with supportive others beyond the supervisors, using three methods 1 ) emails to 150 graduates and supervisors from the international $\mathrm{PhD}$ programme who attended a reunion; 2 ) verbal invitation (responded to confidentially after the session) in the UK and international workshops with postgraduates and supervisors (25 workshops, 2015-6). 11 postgraduates/graduates and 5 supervisors who have used such support or are aware of it being used were interviewed as a result. Also interviewed through their referrals were a range of enabling 'others' (4) in the 'penumbra' supporting doctoral student research journeys. Questions explored the range, extent and kind of support. The approach aimed to ensure topical relevance and the semi-structured interview guide explored issues of support.

In our own discussions and from the data from those we interviewed there emerged, and 
then we developed, the metaphor of the 'penumbra' to suggest 'lightside' and 'darkside', accompaniment to and support of doctoral student work, and a metaphor of dramatic production to offer a perspective on the support, production, performance, staging and sharing of the doctoral student journey, experience and final thesis work.

\section{Data analysis: Thematic coding: 'Penumbra', dramatic performance-roles}

The thematic analysis of the data identified themes and raised issues of ownership, identity, ethics, authenticity and community. In our thematic and theory-informed coding, we made use of the open and explorative coding approach described by Saldana (2016) linked to methods of close reading within qualitative research (Brummett, 2010). We suggest dramatic production and theatre offer a useful metaphor to explore the variety of performers and acknowledged or hidden support involved in producing doctoral work. Possibly Aristotle's Poetics c. 33 BCE is the earliest use of dramatic theory, relating the human experience to drama and theatre. More recently, Goffman used the theatre metaphor to explain human behaviour arguing individuals perform actions in everyday life as if performers on a stage (Goffman, 1959). Berghegger (2009) suggests that figures such as Stanislavsky, Moreno and Sarbin also compare drama to life. In higher education research literature the use of drama and theatre serve as metaphors for understanding teaching and learning practices. Land (2004) uses different metaphors for understanding institutional culture, and Barnett (2000) uses metaphors of the sacred and profane to discuss the role of the university in contemporary society. Also useful are Parker's metaphors of 'theatre' and 'race track' to analyse competing discourses in higher education learning and teaching (2005). Winnicott's conception of 'serious play', underpins the argument that the theatre metaphor makes visible higher education as a "challenging place, for students, researchers and teachers alike: making demands for engagement with potentially alien identities and thought systems that challenge the stability of identity, of knowledge and of normative values." (Parker, 2005, p. 153).

Exploring the data and using theatre metaphors of drama and stage, we identified roles and actions, some aiding the production, some substituting for the student's effort, asking: who are those in support?, who are the players in the 'penumbra' of unacknowledged help?, what do they do to support the work? How legitimate is their support? We divided supporters and producers into frontstage, backstage and the dark recesses of the stage, 'lightside' and 'darkside'.

We found that there are many positive, supportive, meaningful others, including family members, translators, editors, research assistants, fellow doctoral students, and critical friends who read and discuss the work, offering comments and improvements, supporting clarity of expression. We also found that there are others - academics, external partners and friends - acting as unofficial supervisors. These recognised and legitimate supporters are an acknowledged 'penumbra', 'lightside', front of house, giving time generously, supporting and encouraging students with the research, the writing, and also offering introductions and networking beyond the thesis. We confine ourselves here mostly to the rarely discussed 'darkside' support.

\section{Findings: Frontstage and backstage doctoral education}

\section{Frontstage: The Director/producer of the 'performance'/appointed supervisors}

With the doctoral student in the main role, the main frontstage actor is the supervisor or supervisors whose work is focused on support and development of the doctoral student's research and thesis. The institutional organisation underpins students' support, acknowledging personal and intellectual advice, making links between supervisors, institution and students. Much has been written about supervisor support, and in this essay/paper? We wanted to focus not on the more obvious support, 
the supervisor, the research development programme, but instead on that support which is often unacknowledged or hidden.

Either frontstage or backstage are critical friends who legitimise/read the thesis, members of seminar groups, and finally often an appointed proof reader or copy-editor taking out typos.

In earlier work (Wisker \& Savin Baden, 2009), one of us discovered a supportive community centring round the writing of a thesis. Doctoral students identified the usefulness of studying the writing of colleagues whose work was recognisable as of a similar level as their own, rather than that of high flying published others (Wisker \& Savin Baden, 2009). They also valued sharing their work with critical friends, in which instance they were able to support each other by acting as second reader, by verbal and marginal written feedback, helping to make the work more readable.

Some universities offer informal support in 'graduate reading groups' and 'graduate writing groups', often run by doctoral students. Friends and other PhD students commenting on early work can act in a similar role to peer reviewers later in the process. Just like peer reviewers, however, it is a good idea to identify those who are critically astute and developmentally supportive rather than destructive. In speaking of reviewing for publication, one respondent noted the usefulness for their own writing, so we can extrapolate that activity in a critical review friendship between doctoral students could have the same effect. The earlier respondent said:

Being part of the reviewing community feeds into other roles, including doctoral supervision, and reviewers frequently encourage PhD students to engage to advance their own careers. (Wisker, 2014)

Writing communities can be helpful in trialling the work by reading it, and there are many established fora for sharing early and finished work. Students deliver their work at internal and external symposia, workshops and conferences and receive and respond to the critical feedback offered by colleagues. They can also derive a great deal of useful focus by delivering at a threeminute thesis competition, where they are expected to produce a single PowerPoint slide summing up the contribution of their work, and to speak to their work accessibly for no more than three minutes. Being able to communicate the main argument, perspective and contribution to knowledge of the research is an essential part of the doctoral learning journey. Somewhat stressful because in front of an audience, such an event, insistent upon clarity and succinct message and the foregrounding of the argument and main contribution to knowledge, is an excellent way of sharing and gaining critical feedback from judges and peers.

\section{Backstage}

Backstage there is also a community of critical friends, likely to include husband/wife/mum/dads and sons and daughters, for example. Such others are often helpful in reading parts of the work or listening to it in development, as they can support the sense-making and accessibility of the argument, offering responses to what has been termed the 'father-in-law' pitch or the 'elevator pitch', in which doctoral students explain very succinctly and in everyday terms what their work is about, why they are undertaking it and how, and what it contributes and might change. This is the layperson's version of the formal three-minute thesis. Such support is well recognised by editors and publishers as an essential element in honing a publishable piece. On the 'lightside', Lingis acknowledges that we legitimately 'speak in the place of others' (1998). 'We present insights, appraisals, and feelings another will make her own' (Lingis, 1998). In The First Person Singular, he argues the value of a collective, as it may recognise the plurality of a discourse (Lingis, 2007). From the perspective of positioning theory, Harre (2003) states that 'interpersonal relations must enter 
into communal forms of remembering, deciding, problem solving and so on' suggesting that it is legitimate to seek the opinion and advice of a range of others.

In our research we discovered a range of less recognised, backstage others useful to students in their work.

Programme administrators might play a significant role backstage, keeping track of students' development with complicated spreadsheets indicating stages of students' work.

Such institutional organisation helps underpin support for students. What one administrator does is to acknowledge personal and intellectual advice, making the link between supervisors, the institution and the students, particularly when students actually can't read what the supervisors have commented on their work because it is in another language to their own, at which point she gets it 'translated'. She also glosses it so that they might be able to interpret more clearly what the supervisors said. This kind of translation, both of the language and the intent, goes way beyond ordinary support, while not obviously substituting for the student's work. Sometimes they gloss interpretation of supervisors' comments, help with organisation and translation.

'I decipher what the supervisor has written. I help them understand it and sometimes I translate it.' (A)

The translator, the editor who partially rewrites/interprets text, is often an acknowledged or an unacknowledged support in the thesis writing, as they are when texts are sent for English language editing before or after being submitted for publication to a journal. In using translators, the level of interpretation and the ownership of the ideas, as well as the words, are issues, but official acknowledgement? Translation is often essential to level the expression playing field, for those for whom English or the language of publication is not their first language.

In this kind of intercultural learning when students study in another culture, language and country, the translator plays also a role of support--helping not only in translating literally, but also in counselling how to elaborate on specific concepts which are culture related. Guardian supervisors can encourage using this kind of support also. (2016: A)

As an English speaker I have been involved in negotiating between supervisors and students, bridging the language barriers, sometimes simply helping decipher the supervisors' email or handwriting, or explaining what might the supervisor mean in his/her messages, as well as bridging the culture gap or explaining the academic culture. (2016: B)

In the context of intercultural learning, the translator is also backstage, playing 'a role of support helping not only in translating literally, but also in counselling how to elaborate on specific concepts which are culture related.' (B)

Backstage, both communities and guardian supervisors play parts in community learning and encouraging support groups:

I have been involved in designing and giving workshops on research methods, writing, conceptualizing ideas, structuring the architecture of the thesis, giving individual guidance and tutoring. (B)

Some of the work these coaches, mentors, guardian or extra unofficial supervisors do is mediating 
the work of the more formal supervisor. Sometimes the work is recognised, paid for by the institution or the student, and sometimes it is less well known, paid or unpaid; it helps translate and encourage understanding.

Some edit students' work, proofread, serve as sounding boards, providing empathy, containing anger and frustration, helping make choices - whether to do qualitative or quantitative research?, to use interviews or focus groups? They provide encouragement, suggest solutions to problems or difficulties, search for materials and articles, help in phrasing and rephrasing, and adjudicating:

Sometimes funny situations would occur when the students were reluctant to tell their supervisors the truth about an issue arising during the $\mathrm{PhD}$ process ... and then the student would want to consult with me whether to conceal this from him or not. (D)

This last leads us onto the issue of the 'darkside'.

\section{Discussion: The 'darkside' of doctoral education and the dark recesses of the stage}

The area of most concern was the dark recesses (like the ghost in Hamlet).The work of some totally hidden supporters and enablers could fall into the 'darkside' of the doctoral process, those who ghost write the PhD, turn vague thoughts into a thesis, whose work could be seen as encouraging deceit and unethical behaviour if passed off as that of the student. For ethical reasons we have no direct quotations acknowledging 'darkside' use. However the examples shared below are developed from anecdotal discussions with students and supervisors in the sample described above, our knowledge of individual practices and from exploration of websites offering a full service substituting for student effort.

Research assistance can become a 'stand-in' role, with research students hiring assistants, and, in more extreme cases, external agencies actually write the thesis. Work has been carried out by Aitchison (2015) on the hundreds of websites providing stand-in writing for students, and charging variable amounts for their production of chapters or whole theses. One in particular one of us exposes in workshops (we shall refrain from providing it with advertising here) offers potential $\mathrm{PhD}$ students the opportunity to have a publishable 40,000-word literature review (far too long) by $5 \mathrm{pm}$ the next day, on a topic of their choice, and ask the student about key texts to inform it. The cost is up to $\mathrm{f24,000}$ for this chapter alone. In their grander version, they offer a 'Royal Explorers' version of a $\mathrm{PhD}$, in which the student can undertake the doctoral and an international journey together, studying issues in international locations (titles offered on the website were all descriptive). They would be accompanied for the three years by an Oxford don (or similar). This is perhaps an enticing or rather unpleasant prospect, and certainly one that would be labelled a 'darkside' activity. The whole costs between $\mathrm{f100,000}$ and $\mathrm{f1}$ million for the three years.

With such blatant, publicly advertised 'darkside' activities, it is time to further study and where appropriate legitimate and support the personal and learning-oriented work of the supportive 'lightside' others who enable doctoral students to achieve their potential and write well, without doing it for them. With startling prescience, given our topic, developing the analogy of dramatic performance, Goffman looks on the 'darkside' of performance in everyday life, expressing some of the characteristics of covertness, pretence, obfuscation. These could be/are part of the engagement with the darkest recesses of 'help for doctoral work, which amounts to substitution and pretence'. He notes:

We sometimes find that ... the performer may be engaged in a profitable form of activity that is concealed from his audience and that is incompatible with the view of his activity 
which he hopes they will obtain. $(1956$, p. 27)

and

...he will tend to show them only the end-product, and they will be led into judging him on the basis of something that has been finished, polished, and packaged. In some cases, if very little effort was actually required to complete the object, this fact will be concealed. (ibid, $p$. 28)

This becomes even darker:

We find that there are many performances which could not have been given had not tasks been done which were physically unclean, semi-illegal, cruel, and degrading in other ways; but these disturbing faces are seldom expressed during a performance. In Hughes' terms, we tend to conceal from our audience all evidence of 'dirty work,' whether we do this work in private or allocate to a servant, to the impersonal market, to a legitimate specialist, or to an illegitimate one. (1956, p. 28)

\section{Conclusion}

Using the metaphor of the theatre and dramatic production, makes visible that doctoral education cannot be reduced to the individual endeavour of the doctoral student nor the dyadic relational work between a supervisor and a student. The PhD is a world of extended drama. We have shown that the PhD can neither be contained in conceptions of dyadic relationships or workplace learning, but needs a more powerful, yet potentially more disturbing, conception of educational theatre in the deep existential and ontological sense (Lingis, 1998; 2007). The conception of the PhD as theatre holds within it dimensions of gothic ontology, where ghosts and darker beings roam in the periphery and grey zones of the formal learning spaces and institutional environments, some good and helpful and legitimate, some less so.

Based on our findings and discussion, we conclude that, like actors, doctoral students should have appropriate support in addition to that of their supervisors, to enable dialogue, knowledge exchange and construction, and final presentation. Many 'lightside' and 'darkside' others have their part to play in the drama that is the $\mathrm{PhD}$, but questions arise concerning what is legitimate and what illegitimate, collegial or individual academic support. Students need guidance on this. The 'darkside' influences could undermine the confidence and authority of the student and supervisor. More worryingly still, some practices, provision, and providers might totally substitute for research and writing efforts, devaluing subsequent skill claims of the doctoral graduate.

It is time to differentiate, expose the covert or blatant, publicly advertised 'darkside' and enable the legitimate 'lightside', personal and learning-oriented work of supportive others who enable doctoral students to achieve their potential and write well, without doing it for them.

When the 'darkside' of substitution replaces authenticity and the student's own work, we must ask 'whose PhD is it?'. This question, which may be said to be the pivotal concluding reflection, points towards further research into the PhD as a joint, collective, and life-world-based academic production.

Our study highlights that we need to discuss further to what extent it makes sense to still see the PhD as an individual effort. We need more knowledge about the darker ways (often tacit, often hidden) in which doctoral students are being supported and helped through their PhD. We suggest that the PhD should be researched further as a site for collective and extra-institutional forms of creativity and originality - something that disturbs the core of our traditional understandings of the PhD. 


\section{References}

Aitchison, C. (2015). Doctoral writing markets: Exploring the grey zone. In Handbook of academic integrity (pp.1-12). Berlin: Springer Science+Business Media.

Bengtsen, S.S.E. (2016a). Doctoral supervision: Organization and dialogue. Aarhus: Aarhus University Press.

Bengtsen, S.S.E. (2016b). An exploration of darkness within doctoral education. Creative learning approaches of doctoral students. In C. Zhou (Ed.), Handbook of research on creative problem-solving skill development in higher education (pp.260-282). Hershey, PA: IGI Global.

Bengtsen, S.S.E., \& Barnett, R. (2016). Confronting the dark side of higher education. Journal of Philosophy of Education. doi:10.1111/1467-9752.12190.

Berghegger, S. (2009). Life as art as life: Dramaturgy as psychology. Inquiries Journal 1(11), 1.

Brinkmann, S. \& Kvale, S. (2014). Interviews. Learning the craft of qualitative research interviewing. Thousand Oaks, CA: SAGE Publications.

Brummett, B. (2010). Techniques of close reading. Thousand Oaks, CA: SAGE Publications.

Carter, S. (2014). Responding to cross-campus student requirements. In S. Carter \& D. Laurs (Eds.), Developing generic support for doctoral students. Practice and pedagogy. London \& New York: Routledge.

Carter, S., \& Laurs, D. (2014). (Eds.), Developing generic support for doctoral students. Practice and pedagogy. London \& New York: Routledge.

Elliot, D.L., Baumfield, V., Reid, K., \& Makara, K.A. (2016). Hidden treasures: Successful international doctoral students who found and harnessed the hidden curriculum. Oxford Review of Education, 42. doi: 10.1080/03054985.2016.1229664

Elliot, D.L., Reid, K., \& Baumfield, V. (2015). Beyond the amusement, puzzlement and challenges: An enquiry into international students' academic acculturation. Studies in Higher Education. http://dx.doi.org/10.1080/03075079.2015.1029903

Goffman, E. (1956). The presentation of self in everyday life (pp. 27-28). New York: Doubleday.

Grant, B. (2001). Dirty work: 'A code for supervision' read against the grain. In A. Bartlett \& G. Mercer (Eds.), Postgraduate research supervision. Transforming (R) Elations. New York: Peter Lang.

Grant, B. M. (2008). Agonistic struggle master-slave dialogues in humanities supervision. Arts and Humanities in Higher Education 7(1), 9-27.

Fitzpatrick, E., Mullen, M., \& O'Connor, P. (2015). Creating CRUAT: Disrupting supervision and research through collaborative performance. NJ: Drama Australia Journal 39(1), 31-44.

Harre, R., \& Moghaddam, F. (2003). (Eds.), The self and others: Positioning individuals and groups in personal, political, and cultural contexts. Praeger, Westport, USA. 
Holstein, J.A. \& Gubrium, J.F. (1995). The active interview. London \& New Delhi: SAGE Publications

Hopwood, N., Alexander, P., Harris-Huemmert, S., McAlpine, L., \& Wagstaff, S. (2011). The hidden realities of life as a doctoral student. In V. Kumar \& A. Lee (Eds.), Doctoral education in international context: Connecting local, regional and global perspectives (pp. 213-233). Serdang: UniversitiPutra Malaysia Press.

Jazvac-Martek, M., Chen, S., \& McAlpine, L. (2011). Tracking the doctoral student experience over time: Cultivating agency in diverse spaces. In L. McAlpine \& C. Amundsen (Eds.), Doctoral education: Researched-based strategies for doctoral students, supervisors and administrators ( $p .25)$. Berlin: Springer Publishing.

Kiley, M., \& Wisker, G. (2009). Threshold concepts in research education and evidence of threshold crossing. Higher Education Research \& Development 28, 431-44.

Lave J., \& Wenger, E. (1991). Situated learning: Legitimate peripheral participation. Cambridge: Cambridge University Press.

Lingis, A. (1998). The imperative. Bloomington and Indianapolis: Indiana Press.

Lingis, A. (2007). The first person singular. Evanston, IL: Northwestern University Press.

Manathunga, C. (2007). Intercultural postgraduate supervision: Ethnographic journeys of identity and power. In D. Palfreyman \& D. L. McBride (Eds.), Learning and teaching across cultures in higher education (pp. 93, 95). Basingstoke: Palgrave Macmillan.

Manathunga, C. (2014). Intercultural postgraduate supervision: Reimagining time, place and knowledge. London \& New York: Routledge.

Marginson et al. (2016). In M. Pearson, T. Evans, \& P. Macauley, The diversity and complexity of settings and arrangements forming the 'experienced environments' for doctoral candidates: Some implications for doctoral education. Studies in Higher Education 41(12), 2110-2124.

McAlpine, L., \& Norton, J. (2006). Reframing our approach to doctoral programs: A learning perspective. Higher Education Research and Development 25(1), 3-17.

McAlpine, L., \& McKinnon, M. (2013). Supervision - the most variable of variables: Student perspectives. Studies in Continuing Education 35(3), 265-280.

McCracken, G. (1988). The long interview. Qualitative Research Methods Series. Thousand Oaks, CA: SAGE Publications.

Morris, C., \& Wisker, G. (2011). Troublesome encounters: Strategies for managing the wellbeing of master's and doctoral education students during their learning processes. HEA ESCalate subject centre report. Retrieved from http://escalate.ac.uk/6828.

Parker,I. (2005) Psychology: Introducing radical research. Maidenhead: Open University Press. 
Saldana, J. (2016). The coding manual for qualitative researchers. London: SAGE Publications.

Turunen, T. (2012). From the countdown to an intermediate stopping point. In K. Määttä, Obsessed with the doctoral theses: Supervision and support during the dissertation process. Rotterdam: Sense Publishers.

Vekkaila, J., Pyhältö, K., \& Lonka, K. (2013). Experiences of disengagement - A study of doctoral students in the Behavioral Sciences. International Journal of Doctoral Studies 8, 61-81.

Wisker, G., (2012) The good supervisor. Basingstoke: Palgrave Macmillan.

Wisker, G. (2014) Managing the writing energy. DoctoralWriting SIG. Retrieved from http://doctoralwriting.wordpress.com/author/doc

Wisker, G., \& Robinson, G. (2012). Picking up the pieces: Supervisors and doctoral 'orphans'. International Journal for Researcher Development 3(2), 39-153.

Wisker, G., \& Robinson, G. (2009). Encouraging postgraduate students of literature and art to cross conceptual thresholds. Innovations in Education and Teaching International 46, 317-330.

Wisker, G., \& Savin-Baden, M. (2009). Priceless conceptual thresholds: Beyond the 'stuck place' in writing. London Research Education 7(3), 235-47.

\section{Websites}

The PhD consultancy: http://www.thephdconsultancy.com/ 